(1872), The Formation of Vegetable Mould, Through the Action of Worms (1881) and five botanical publications. J. B. S. Haldane insisted that Darwin's highly original botanical work was as important as his publications on evolution. In some of this research, Darwin showed what an active and successful experimenter he was.

When evaluating this book we must remember that Browne is a historian and biographer, not an evolutionist. This is why she does not feel that it is her job to analyse Darwin's evolutionary paradigm (his five major theories) or to explain the principle of divergence and how it misled Darwin, or why he ultimately failed to solve the problem of the multiplication of species, which had been his major objective when starting to work on his "species book", or to try to explain numerous other evolutionary problems that he encountered but left without explanation. For answers to these questions one will have to turn to other books.

Alas, there still is no satisfactory presentation and analysis of Darwin's whole evolutionary paradigm. My One Long Argument (1997) has a short treatment of these problems but, by necessity, does not refer to some of the most recent controversies and findings. To supplement Browne's superb treatment of Darwin, the man and his period, we now need a deep analysis of his work. But this requires a real understanding of evolution, and such an understanding is not very common.

Ernst Mayr is at the Museum of Comparative Zoology, Harvard University, Cambridge, Massachusetts 02138, USA.

\section{Reaching for the Moon}

\author{
The Lunar Men: Five Friends \\ Whose Curiosity Changed \\ the World \\ by Jenny Uglow \\ Farrar, Straus \& Giroux: 2002. 608 pp. \\ $\$ 30, £ 25$
}

\section{Robert Bud}

Looking back to the second millennium $\mathrm{AD}$ from a great distance in time, the Industrial Revolution might be the only distinctively British feature visible. With a shorter perspective but after a generation of revisionist examination, it seems that something historically unique and world-changing did indeed happen first in Britain during the late eighteenth century. Just when Adam Smith was showing how specialization could lead to steady economic growth, massive technological change began to make possible a quite different kind of growth, transforming an agrarian into a manufacturing economy. There was also a consciousness that revolutionary changes were in the air, though what and which would be the most important in that era of American independence and French regicide remained unclear. This book takes the reader on a journey in that topsy-turvy time by following the details of a group of individual lives.

Your guide is not the universal historian, but history is a broad church, requiring the collaboration of people with many different skills. Some are remarkable analysts, some imaginative lateral thinkers. Others are expert weavers of tales from the fractured evidence of manuscripts and secondary accounts. Jenny Uglow is a brilliant weaver. She has brought a distinct and wonderful contribution to a subject that has been plentifully studied from other perspectives.

The tale of the Lunar Society of Birmingham is well known to the professional historian of eighteenth-century Britain. A loose club of remarkable pioneers living in the West Midlands (and meeting when the Moon was full, to make homeward journeys safer along unlit roads), it included Josiah Wedgwood, founder of the great pottery; Joseph Priestley, 'discoverer' of oxygen: and James Watt of steam-engine fame. It was among the first of that genre of Industrial Revolution associations, which included Benjamin Franklin's American Philosophical Society and the Manchester Literary and Philosophical Society to which the atompioneer John Dalton belonged.

One reason for the plentiful studies of the Lunar Society is that its members were both prolific inventors of labour-saving devices and laborious writers of letters. Despite losses over 200 years, vast archives of their daily correspondence are still to be found, now carefully catalogued. The letters, not all of which are legible to modern readers, mix business news, gossip and all the elaborate dance of competitive men, conscious of their place in history, communicating with friends who are also rivals in the social world. Even if much of the core narrative already exists, Jenny Uglow is the first to draw so expertly on the texture of the correspondence to weave a picture of the relationships of these men and the world they inhabited.

The book draws not just on the manuscripts but also on two generations of scholarship, including the most current. Along with the sense of human relations there is also a judicious allocation of credit, taking account of recent judgements. The work is not a new analysis in the history of science and technology, but this is not exactly popular history either. When the author refers to 1759 as "that year of victories", she presumes a level of cultural familiarity that may not now be universal. Who today can name Britain's victories against the French that year, never mind understand the significance of the battles of Quiberon Bay or Lagos Bay?

At one level the book can be read almost as a novel of the period, with its pointillist detail and telling social comment. But its ambitions are greater. At various points the reader is encouraged to observe the significance of the Lunar Men and their world to

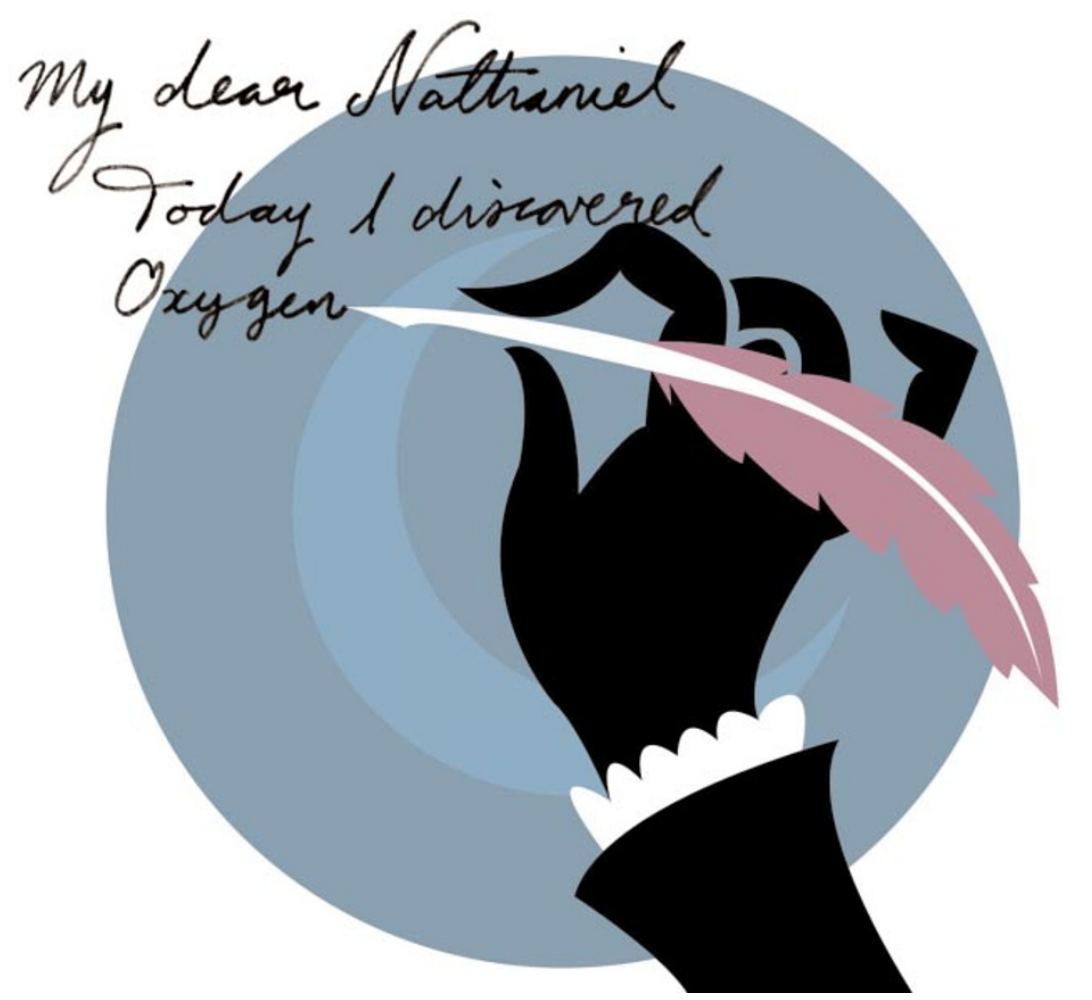


the reading of the Romantic writers such as Samuel Taylor Coleridge. The conclusion almost wistfully points to the end of an optimistic world and the onset of the romantic period that "spurned the arid insights of reason and the denial of innate instincts". In a sense, therefore, Uglow, who is honorary professor of English and comparative literature at Warwick University, is in a specific dialogue with readers of the Romantics, urging them to look to the context of the Lunar Men and their concerns.

The specificity of the audience points perhaps to a weakness in the book. It will be enjoyed by many even if they do not pick up every allusion, but scientists may be surprised that the author does not put the Lunar Society into its context in scientific history. The Lunar Men were succeeded not just by the Romantic poets, but also by the British Association for the Advancement of Science, founded in 1831 with such a diverse membership of enthusiasts that William Whewell felt compelled to invent a new name to describe them: "scientists".

Moreover, although the technological meaning of science is well covered - one might even say exaggerated - its cultural function of aiding understanding of a new, complex, urban, multi-ethnic, multi-class world is neglected. What was the place of the Lunar Men as a group in the Industrial Revolution? Uglow will imply their centrality, but does not decisively address the point. So could the book be better? Certainly many of its readers will go away with unanswered questions and a wish to argue with the author. But that is to attest to achievement, not failure.

Robert Bud is at the Science Museum,

Exhibition Road, London SW7 2DD, UK.

\section{Einstein brought up to speed}

The Curvature of Spacetime: Newton, Einstein, and Gravitation by Harald Fritzsch

Columbia University Press: 2002. 341 pp. \$29.95, £20

\section{Francis Everitt}

When Daniel Defoe's fictional castaway Robinson Crusoe finally collected his thoughts on 30 September 1659, on the lonely island where he would remain for 28 years, 2 months and 19 days before returning to England in 1687, the year Newton's Principia was published, his first action was to write down in the notebook he had providentially saved from the wreckage a debit-credit account of his state in two columns, Evil and Good. Physicists on their island, no less remote, despite being linked

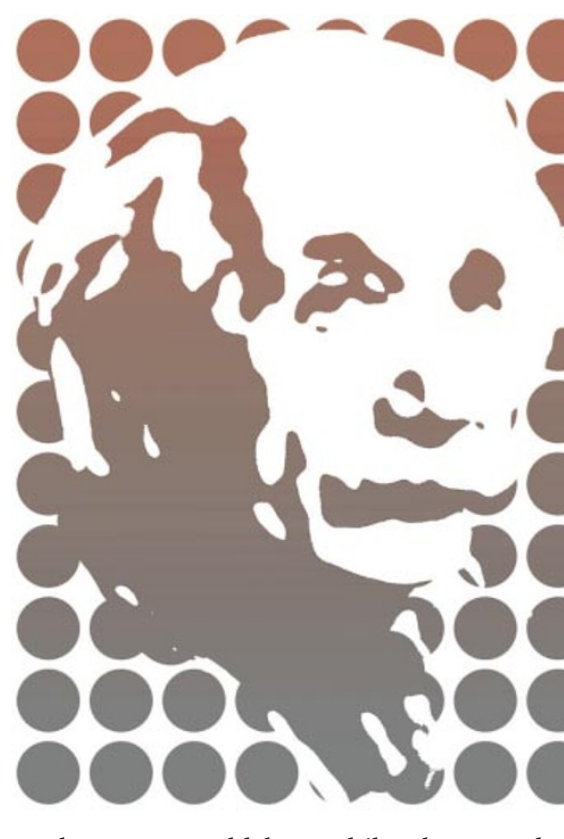

to the outer world by mobile phone and Internet, might well set down a similar debit-credit sheet. Knowing so much, they might start with just one column, headed Good, but eventually comes the need to list in an Evil column a few of the many things we don't understand.

Harald Fritzsch's The Curvature of Spacetime is a time-travel dialogue set in 1996 between three men: Isaac Newton, aged 45 after completing the Principia; Albert Einstein at 51, riding the triumph of relativity; and an imaginary modern expert, Adrian Haller. They meet in various German locations familiar to Einstein, and then at Caltech, where Einstein had spent time in the 1930s. As an expository device, the dialogue form is quite successful. It lets Haller teach Einstein and Newton (and us) the current status, experimental and theoretical, of particle physics, drawing the reader into exchanges of view and conflicting ideas more readily than conventional exposition would allow.

The format is problematic historically, however. We find that Newton apparently knows everything about physics up to about 1890 , yet is fogged and slow on the uptake about Einstein's work. Newton had faults Fritzsch deliberately passes over certain 'disagreeable' aspects of his character — but slowness of uptake was not one of them. And is it pedantry to object to Haller's "reminding" Einstein (in a book containing no mention of Ernest Rutherford) that in 1896 "Henri Becquerel found out that the atomic nucleus of uranium is unstable"? This must have been quite a feat before $\alpha$-particles, $\beta$-particles and $\gamma$-rays were known, the electron was discovered, or Rutherford had proposed the nucleus.

Taken literally, Fritzsch's title is misleading. Much of the book is about particle

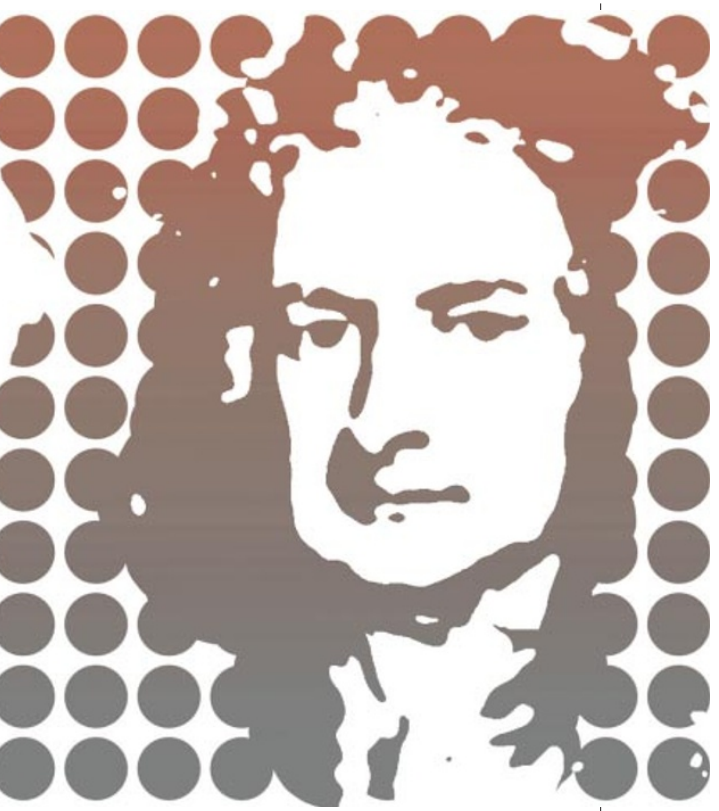

physics, rather than gravity or spacetime. However, this expansion benefits the content; it reveals how far physics has come since Einstein and shows off Fritzsch's considerable gifts as an expositor.

Both Newton and Einstein puzzled over the meaning of mass. Particle physics has failed to illuminate them: the large unexplained range of masses of elementary particles from neutrinos to quarks has only complicated matters still further. Reading Fritzsch on these issues, including his account through Haller of how the Large Hadron Collider at CERN, the European Laboratory for Particle Physics, will (we hope) reveal the Higgs particle and explain mass, leads to the deeper question of what constitutes explanation in physics.

One of Newton's discoveries, often wrongly credited to Galileo, was that in physics, mass fulfils two functions. According to the law of acceleration, mass is the receptacle of inertia; the inverse-square law of gravity makes it the source of gravitation. The masses in these equations are said to be 'equivalent'. Equivalence is often said to be incomprehensible in Newton's physics but explained in Einstein's. Einstein's falling elevator made inertial and gravitational accelerations indistinguishable; this indistinguishability became a principle; curved spacetime followed. And so, Fritzsch has Einstein saying that gravitational and inertial accelerations are not only proportional to each other, but "completely identical".

But surely something is wrong. Complete identity means, in ordinary language, no difference. If there is no difference between inertia and gravity, why does physics need a gravitational constant? Einstein is credited with removing unnecessary concepts he eliminated the ether, and consolidated 